\title{
Myomectomy during Caesarean Section: Safety and Feasibility of the Procedure
}

\author{
HOSNE ARA BABY ${ }^{1}$, MOSAMMAT RASHIDA BEGUM ${ }^{2}$, MARIYA EHSAN ${ }^{3}$, NAZIA EHSAN ${ }^{4}$, IFTEKHAR \\ AMIN $^{5}$, ASHIK AHMED CHOWDHURY ${ }^{6}$, FARZANA KHAN ${ }^{7}$, FARHANA SHARMIN ${ }^{8}$, \\ MOSAMMAT SHAHINABEGUM ${ }^{9}$
}

\begin{abstract}
:
Objective (s): Aim of the study was to evaluate the safety and feasibility of myomectomy during cesarean section.

Materials and methods: This prospective observational study was carried out in a private setting at Dhaka city from January 2006 to June 2015. Forty five (45) women with fibroid uterus with pregnancy who needed caesarean section were the target population for this study. Myomectomy was done during caesarean section. Main outcome measures were: difficulty of myomectomy and caesarean section, time needed for operation, per-operative complications, need for blood transfusion, postoperative complications and duration of hospital stay.

Results: During the study period total 45 women were found who had pregnancy with myoma and needed caesarean section for various indications. Twenty nine (64.4\%) women were of age 26-35 years, 30 (66.7\%) were para 0 and in 37 (82\%) cases were term pregnancy. In forty one (91.1\%) cases myomas were diagnosed preoperatively. Twenty five (55.6\%) women had multiple myomas. Commonest site of myoma was body of the uterus (82.2\%) and commonest type was intramural (75.6\%). Thirty (66.7\%) women had myoma of less than $5 \mathrm{~cm}$ in size. In forty two (93.3\%) cases myomectomy was done after delivery of the baby. Myomectomy was successful in all 45 (100\%) cases. In thirty (80\%) cases caesarean myomectomy was completed within 1 hour. Thirty seven (82.2\%) women did not need blood transfusion and thirty eight (84.4\%) women had no postoperative complication. Other had minor complications. Forty one (90.1\%) women were discharged from hospital within 72 hours of operations.

Conclusion: Myomectomy during cesarean section is a safe procedure and it is feasible in almost all cases. Though large scale RCT is needed before giving final conclusion it is not far away when myomectomy during cesarean section will be norm discarding the traditional view of not touching the myoma in pregnancy
\end{abstract}

Key words: Myoma, Myomectomy, caesarean myomectomy

\section{Introduction:}

Myoma is the commonest tumor of the uterus occurring in women of childbearing age. It is found approximately $2 \%$ of pregnant women. ${ }^{1}$ Myoma may adversely affect the pregnancy and depending on the size and site may be the cause for cesarean delivery. But routine myomectomy during prergnancy is not advocated for the risk of bleeding and abortion. Indications of myomectomy during pregnancy include sever pain due to torsion of subserous pedunculated

1. Consultant, Infertility Care and Research Center

2. Chief Consultant, Infertility Care and Research Center

3. Ex Medical Officer, Infertility Care and Research Center

4. Medical Officer, Infertility Care and Research Center

5. Medical Officer, Infertility Care and Research Center

6. Medical Officer, Infertility Care and Research Center

7. Senior Medical Officer, Infertility Care and Research Center

8. Medical Officer, Infertility Care and Research Center

9. Consultant, Infertility Care and Research Center 
myoma or red degeneration not responding to treatment and an increase in myoma size causing abdominal discomfort. ${ }^{2}$ But myomectomy during cesarean section is different from that of during pregnancy. Previous studies have reported that it is better to avoid myomectomy during cesarean section except for small pedunculated fibroid. ${ }^{3,4,5}$ Because during pregnancy size and vascularity of myoma increases and there may be excessive haemorrhage during myomectomy and the difficulty in securing hemostasis may need hysterectomy. But the fact and newer studies described the advantages of myomectomy during cesarean section. These are:

Myomectomy during caesarean section would cause less bleeding because at post partum the uterus is better adopted for control of hemorrhage as the uterine muscles are more sensitive to oxytocic agents and removal of myoma enable the uterus for better contraction. Moreover, the pregnant patients are in hypervolumic and hypercoagulable state, so can cope easily with a certain amount of blood loss.

- Enucleation of myoma is easier as the capsules become loose.

- It avoids the risk of another surgery and anesthesia for removal of myomas.

- Cost effective. $^{6}$

- Avoid classical cesarean section in case of myoma presenting at lower uterine section.

- Facilitate the chances of vaginal delivery in subsequent pregnancies when myoma removed from lower uterine segment. ${ }^{7}$

- Reduces the complications associated with fibroid in subsequent pregnancies. ${ }^{8}$

- The scar integrity following caesarean myomectomy has been shown to be better than that following interval myomectomy. ${ }^{9,10}$

- Enable to keep the patient's request (most of the patients want to remove the myoma during caesarean section)

So the purpose of this study was to evaluate the safety and feasibility of doing myomectomy during cesarean section.

\section{Methods and Materials:}

This prospective observational study was carried out in a private setting at Dhaka city from January 2006 to June 2015. Forty five (45) women with the following criteria were the candidate for the study-
1. The women with a diagnosed myoma in the uterus became pregnant and needed caesarean section for various indications.

2. The women who are diagnosed to have myoma along with pregnancy during antenatal check up and needed C/S for various indications.

3. The women who are incidentally diagnosed to have myoma during cesarean section.

Operations were done by two senior gynaecologists in two private clinics. Patients were informed about the risks and benefits of myomectomy during caesarean section. Informed consent was taken before operation in diagnosed cases and during operation in incidental cases. Blood donors were kept ready during operation. Myomectomy was done by conventional technique as in non-pregnant uterus. But timing of removal of myoma and delivery of the baby was dependent on individual situation. Oxytocin infusion was maintained during and for 24 hours after the operation. Main outcome measures were: difficulty of myomectomy and caesarean section, time needed for operation, per-operative complications, need for blood transfusion, postoperative complications and duration of hospital stay.

\section{Results:}

During the study period total 45 cases of caesarean myomectomy were done. Table-1 shows the distribution of mothers according to age, parity and gestational age at caesarean section. Twenty nine (64\%) women were of $26-35$ years of age. Thirty (66.7\%) women were primiparous. In 37 (82\%) cases caesarean section were done at term. Table 2 depicts distribution of mothers according to characteristics of myoma. In 30 (66.7\%) cases myomas were diagnosed before pregnancy, $11(24.4 \%)$ cases during pregnancy and only 4(8.9) cases diagnosed incidentally during caesarean section. Twenty (44.4\%) women had single myoma and twenty five (55.6\%) had multiple myomas. Seven $(15.6 \%)$ women had myoma in the fundus, $22(48.9 \%)$ had in the body of the uterus and $15(33.3 \%)$ had both in the body and fundus of the uterus. Only $1(2.2 \%)$ had myoma in the cervix. Nine (20\%) women had subserous, $25(55.6 \%)$ had intramural, $9(20 \%)$ had both subserous and intramural and 2(4.4\%) had intramural and submucous myomas. In thirty (66.7\%) women size of the myoma were less than $5 \mathrm{~cm}$, in $11(24.4 \%)$ women it varied from $5-10 \mathrm{~cm}$ and in $4(8.9 \%)$ women it was more than $10 \mathrm{~cm}$ in size. Table 3 gives the details of per-operative and post-operative events. In 42(93.3\%) women myomectomy was done after delivery of the baby but in rest $3(6.7 \%)$ cases it was done before delivery as the myomas were in the line 
of incision. Myomectomy was successful in all cases. None of the cases myoma was left behind. Operative time was $<45 \mathrm{~min}$ in $10(22.2 \%)$ women, $45-<60 \mathrm{~min}$ in 26(57.8) cases and 60-90 min in 9(20\%) cases. Blood transfusion was needed in 8(17.8\%) women, one unit in 7 women and 2 units in one woman. Blood transfusion was needed in those cases where myomectomy were done before delivery of the baby and also in cases of large intramural myoma. During postnatal period 6(13.33\%) patients developed mild fever and $1(2.2 \%)$ developed wound infection. Thirty eight (84.4\%) women had uneventful postoperative period. Forty one $(91.11 \%)$ women discharged between 48 and 72 hours and only 4(8.9\%) women discharged after 72 hours.

Table-I

Patients characteristics

\begin{tabular}{lcc}
\hline Parameters & Mean & \pm SD \\
\hline Age (Yrs) & 30 & \pm 2.89 \\
Gestational Age (Weeks) & 37 & \pm 1.56 \\
Parity & $\mathrm{N}$ & $\%$ \\
0 & 30 & 66.70 \\
1 & 11 & 24.40 \\
$\geqq 2$ & 4 & 8.90 \\
\hline
\end{tabular}

Table-II

Characteristics of myoma.

\begin{tabular}{lcc}
\hline Variables & $\mathrm{N}$ & $(\%)$ \\
\hline Diagnosis of myoma & & \\
$\quad$ Before pregnancy & 30 & 66.7 \\
$\quad$ During pregnancy & 11 & 24.4 \\
$\quad$ During cesarean section & 4 & 8.9 \\
Number of myoma & & \\
$\quad$ Single & 20 & 44.4 \\
2-5 & 21 & 46.7 \\
$\quad$ 5 & 4 & 8.9 \\
Location of myoma & & \\
$\quad$ Fundus of the uterus & 7 & 15.6 \\
$\quad$ Body of the uterus & 22 & 48.9 \\
$\quad$ Both fundus \& body & 15 & 33.3 \\
$\quad$ Cervix & 1 & 2.2 \\
Types of myoma & & \\
$\quad$ Subserous & 9 & 20.0 \\
$\quad$ Intramural & 25 & 55.6 \\
Intramural \& subserous & 9 & 20.0 \\
$\quad$ Inramural \& submucus & 2 & 4.4 \\
Size of myoma(cm) & & \\
$\quad<5$ & 30 & 66.7 \\
5-10 & 11 & 24.4 \\
$\quad>10$ & 4 & 8.9 \\
\hline
\end{tabular}

Table-III

Outcome of myomectomy

\begin{tabular}{lcc}
\hline Variables & Number & $\%$ \\
\hline Timing of myomectomy & & \\
$\quad$ Before delivery of the baby & 3 & 6.7 \\
$\quad$ After delivery of the baby & 42 & 93.3 \\
$\begin{array}{l}\text { Myomectomy -success } \\
\quad \text { Successful }\end{array}$ & 45 & 100 \\
$\quad$ Unsuccessful & 0 & 0 \\
Time needed for surgery (min) & & \\
$\quad<45$ & 10 & 22.2 \\
$\quad 45-<60$ & 26 & 57.8 \\
$\quad 60-90$ & 9 & 20.0 \\
Need for blood transfusion & & \\
$\quad$ Yes & 8 & 17.8 \\
$\quad$ No & 37 & 82.2 \\
Postoperative Complications & & \\
$\quad$ Postoperative Fever & 6 & 13.33 \\
$\quad$ Wound infection & 1 & 2.2 \\
$\quad$ No complication & 38 & 84.4 \\
Post surgical hospital stay(hours) & & \\
$\quad 48$-72 & 41 & 91.11 \\
$\quad>72$ & 4 & 8.9 \\
\hline
\end{tabular}

\section{Discussion:}

Incidence of pregnancy with myoma is increasing because of late marriage and childbearing and the increasing use of ultrasonography. Removal of myoma during cesarean section is preferred by the patient and satisfactory for the obstetricians and has several advantages. But traditionally myomectomy had been discouraged during cesarean section because of fear of life threatening bleeding, which may turn to hysterectomy. But during the last decade several studies were done showing the safety of myomectomy during cesarean section.

There are several observational studies where myomectomy was successful in all selected cases. ${ }^{11-}$ 15. In several case control studies also myomectomy was successful in all cases. ${ }^{8,15-23 .}$

In present study 93\% cases myomectomy were done after delivery of the baby but in 3(6.7\%) cases where myomas were in lower anterior wall, myomectomy were done before delivery of the baby to avoid incision in the upper uterine segment. In other studies also myomectomy were done before delivery of the baby when present in lower anterior wall. ${ }^{12,} 24$. 
This shows that myomectomy before delivery of the baby is also feasible when needed. Though there may be chance of more bleeding as devascularization is not possible. In present study in most of the cases myomas were diagnosed preoperatively and operations were done with proper preparations and written consent of the patient. But in 4 cases myomas were diagnosed incidentally during cesarean section. Even then myomectomy were done with the consent of the patient's husband or guardian. This situation was not described and probably not aroused in other studies.

Myomectomy was done irrespective of number, size, type and location of the myomas. In twenty one (46.7\%) cases number were $2-5$ and in $8.9 \%$ cases number was more than 5 . In other studies also multiple myomas were removed ${ }^{8,11,17-21,23.24}$. Most common location was body of the uterus (82.2\%) and type was intramural (80\%). The same is true in most of the

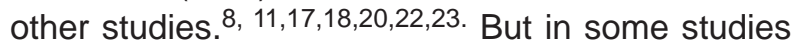
subserous type were more common. ${ }^{19,} 21,24$. Size varied from $5-10 \mathrm{~cm}$ in $24.5 \%$ cases and $8.9 \%$ cases size was $>10 \mathrm{~cm}$. Other studies also reported the removal of large myomas. 17, 18,21,23,24.

In the present study the operative time was $45-<60$ min in $57.8 \%$ cases and $60-90$ min in $20 \%$ cases. This is more than the usual time of caesarean section in our settings which is $30-45 \mathrm{~min}$. Extra time was needed in cases where multiple myomas and or large intramural myomas were removed. In other studies the operative time of caesarean myomectomy is higher than that of caesarean section alone but that was not statistically significant. ${ }^{8,11-24}$. Besides this the benefit of caesarean myomectomy outweighs the risk of this increase operative time. During operation 37(82.2\%) women had no complications in the present study. But 8(17.8\%) women had moderate bleeding for which 1-2 unit of blood was transfused. No patient had lifethreatening bleeding to sacrifice the uterus. Though we could not measure the amount of blood loss, we assess the effect of loss by clinical condition of the patient. Signs of hypovolumia lead to give blood transfusion and amount of blood was transfused according to demand of the patient. In some other studies no blood transfusion was needed at all. $8,14,15,19,22,24$. In other studies blood transfusion was needed in some cases but when compared with control it was not statistically significant. ${ }^{11-13,16-}$ $18,20,21,23$. None of those cases of their series needed hysterectomy. Only in an older study 3 of the 9 cases had sever hemorrhage and required hysterectomy. ${ }^{25}$ Due to improvement of surgical skill, surgical technique, availability of blood and anaesthetic procedure it became possible to manage the cases with severe intrapartum haemorrhage. Proper devascularization and experienced obstetricians can reduce the incidence of haemorrhage and hysterectomy. Forty one (84.4\%) cases of the present study had no postoperative complications and only $4(8.9 \%)$ women had to stay in the hospital for more than 72 hour. In the other studies there were either no complications or small percent of mild complications, which is not statistically significant. In some cases hospital stay was increased by 1-3days. ${ }^{8,}$ 13-26

In conclusion it can be said that myomectomy during caesarean section is a safe procedure and it is feasible in almost all cases. Though large scale RCT is needed before giving final conclusion it is not far away when myomectomy during caesarean section will be norm discarding the traditional view of not touching the myoma in pregnancy.

\section{References:}

1. Katz VL, Dotters DJ, Droegemueller W. Complications of uterine leiomyomas in pregnancy. Obstet Gynecol 1989;73: 593-6.

2. Burton CA, Grimes DA, March CM. Surgical management of leiomyoma during pregnancy. Obstet Gynecol 1989;74: 707-9.

3. Davis JL, Ray Mazumder S, Hobel CJ, Baley $\mathrm{K}$, Sasson D. Uterine leimyomas in pregnancy: a prospective study. Obstet Gynecol 1990;75:41-4

4. Hasan F, Arumugan K, Sivanesaratnam. Uterine leiomyoma in pregnancy. Int. J Gynaecol Obstet 1991; 34: 45-8.

5. Ortac F, Güngör M, Sönmezer M. Myomectomy during cesarean section. Int J Gynecol Obstet 1999; 67:189-90.

6. Akinyinka O. Omigbodun and Adeniran O. Fawole. Myomectomy during pregnancy and delivery: is it safe? Trop J Obstet Gynaecol 2005;22(1):1-3.

7. Omar SZ, Sivanesaratnam V, Damodaran P. Large lower segment myoma: Myomectomy at lower segment section - a report of two cases. Singapore Med J 1999;40:109-10. 
8. Kwawukume EY. Caesarean myomectomy. Afr $\mathrm{J}$ of Reprod Health 2002;6(3):38-43.

9. Cobellis L, Messali EM, Satradella L, Pecori E, Cobellis G. Restitutio ad integrum of myomectrium after myomectomy. Different result in pregnant and non-pregnant patients. Minerva Ginecol 2002;54:393-5.

10. Cobellis L, Messali EM., Satradella L, Pecori E, Gionio E. De Lucia E, et al. Myomectomy during caesarean section and outside pregnancy. Different outcomes of scars. Minerva Ginecol 2002;54:483-6.

11. Ahikari S, Goswami S. Cesarean myomectomyA study of 14 cases. J Obstet Gynecol India 2006;56(6):486-8.

12. Machado LS et al. Caesarean Myomectomy: Feasibility and safety. Sultan Quaboos Univ Med J. 2012;12(2):190-6.

13. IncebiyikA, Hilali NG, Camuzcuoglu A, Vural M, Camuzcuoglu $\mathrm{H}$. Myomectomy during caesarean: a retrospective evaluation of 16 cases. Arch Gynecol Obstet. 2014;289(3):56973.

14. Celal $\mathrm{K}$ et al.The evaluation of myomectomies performed during cesarean section in our clinic. Niger Med J. 2011;52(3):186-8.

15. Ehigiegba AE, Ande AB, Ojobo SI. Myomectomy during caesarean section. Int J Gynaecol Obstet 2001;75:21-5.

16. Brown D, Fletcher HM, Myrie MO, Reid M. "Caesarean myomectomy - a safe procedure. A retrospective case controlled study," J Obstet and Gynaecol.1999;19(2): 139-41.

17. Roman AS, Tabsh KMA. Myomectomy at time of caesarean delivery; a retrospective cohort study. BMC Pregnancy and Child birth 2004;4:14-7.
18. Kaymak O. Ustunyurt E. Okyay RE. Kalyoncu S. Mollamahmutoglu L. Myomectomy during Caesarean section. International Journal of Gynaecology \& Obstetrics 2005. 89(2):90-3.

19. Hassiakos D. Christopoulos P. Vitoratos N. Xarchoulakou E. Vaggos G. Papadias K. Myomectomy during cesarean section: a safe procedure? Annals of the New York Academy of Sciences 2006. 1092:408-13.

20. Owolabi AT, Kuti O, Loto OM, Makinde ON, Adeyemi AB. Caesarean myomectomy- a safe procedure: a retrospective case control study. Nepal J Obstet Gynecol 2007;2(2): 59-62.

21. Park BJ, Kim YW, "Safety of caesarean myomectomy," J Obstet and Gynaecol Res. 2009; 35(5): 906-11.

22. Lin JY, Lee WL, Wang PH, Lai MJ, Chang WH, Liu WM. Uterine artery occlusion and myomectomy for treatment of pregnant women with uterine leiomyomas who are undergoing cesarean section. J Obstet Gynaecol Res. 2010;36(2):284-90.

23. Simsek $Y$, Celen $S$, Danisman N,Mollamahmutoglu L. Removal of uterine fibroids during cesarean section: a difficult therapeutic decision. Clin Exp Obstet Gynecol. 2012;39(1):76-8.

24. Agarawal $\mathrm{K}$ et al. Caesarean Myomectomy: Prospective Study. NJIRM 2011; 2(3) : 11-14.

25. C. Exacoustos and P. Rosati, "Ultrasound diagnosis of uterine myomas and complications in pregnancy," Obstetrics and Gynecology. 1993;82(1): 97-101.

26. Li H. Du J. Jin L. Shi Z. Liu M. Myomectomy during cesarean section. Acta Obstetricia et Gynecologica Scandinavica . 2009; 88(2): 183-6. 